GABRIELA AFONSO ADAMO

\title{
CARTEL EM LICITAÇÃO: O PAPEL DOS PROGRAMAS DE COMPLIANCE EM SUA PREVENÇÃO.
}

Dissertação de Mestrado

Orientador: Professor Doutor Vinicius Marques de Carvalho

UNIVERSIDADE DE SÃO PAULO

FACULDADE DE DIREITO

SÃO PAULO - SP

2018 
GABRIELA AFONSO ADAMO

\title{
CARTEL EM LICITAÇÃO: O PAPEL DOS PROGRAMAS DE COMPLIANCE EM SUA PREVENÇÃO.
}

Dissertação para a obtenção do título de Mestre em Direito Comercial pela Faculdade de Direito da Universidade de São Paulo.

Orientador: Professor Doutor Vinicius Marques de Carvalho

\author{
UNIVERSIDADE DE SÃO PAULO \\ FACULDADE DE DIREITO \\ SÃO PAULO - SP \\ 2018
}


Banca Examinadora 
"Malandro que é malandro não bobeia.

Se malandro soubesse como é bom ser honesto

Seria honesto só por malandragem"

Jorge Ben Jor (1972). 


\section{RESUMO}

ADAMO, Gabriela Afonso. Cartel em licitação: o papel dos programas de compliance em

sua prevenção. Dissertação (Mestrado). Faculdade de Direito da Universidade de São Paulo. São Paulo, 2018.

A presente dissertação objetiva a análise sistemática da prática de condutas colusivas, especialmente o cartel, em procedimentos licitatórios realizados pela Administração Pública.

Inicialmente, pretendeu-se delinear as principais características relacionadas à elaboração de programas de compliance antitruste eficientes, em especial a necessidade de regras específicas voltadas às empresas atuantes em mercados de aquisições públicas. Em um segundo momento, avaliou-se a prática de cartel como um risco comum em procedimentos licitatórios regidos pela legislação brasileira, bem como as possíveis consequências destas infrações. Após, e a partir da análise da jurisprudência do Conselho Administrativo de Defesa Econômica - CADE, pretendeu-se avaliar quais métodos colusivos foram usualmente adotados pelos agentes econômicos que participaram de cartéis em licitação, ao que se denominou a tipologia dos ilícitos. Por fim, estabelecidas tais premissas, concluiu-se pela necessidade do desenho de um programa de compliance voltado a tais organizações, determinando-se os principais métodos a serem adotados pelos gestores de companhias atuantes em mercados de licitações públicas para a eficaz prevenção e detecção de infrações antitruste.

Palavras chave: compliance, antitruste, cartel em licitações, programas de compliance, governança corporativa. 


\begin{abstract}
ADAMO, Gabriela Afonso. Bid riggings: compliance programs as effective tools to prevent violations. Masters of Laws. University of São Paulo. São Paulo, 2018.

This paper aims at systematic analyzing collusive behaviors, specifically cartel infringements in bid proceedings carried out by Public Administration. First, the present work outlines the main characteristics related to efficient antitrust compliance programs, focusing on the need of specific dispositions aimed at companies operating in public procurements. In a second moment, cartel was assessed as a probable risk in the bidding procedures governed by Brazilian law, and possible consequences of these infractions were considered. After, and from the analysis of the jurisprudence of the Administrative Council of Economic Defense - CADE, this paper evaluates which collusive methods were usually adopted by the companies involved in bid riggings. Finally, after these premisses were stated, it was concluded that there is a need to design specific compliance programs for such corporations, and it was determined the main methods which could be adopted by management for effective prevention and detection of antitrust infringements in public procurements.
\end{abstract}

Key words: compliance, antitrust, bid rigging, compliance programs, corporate governance. 


\section{SUMÁRIO}

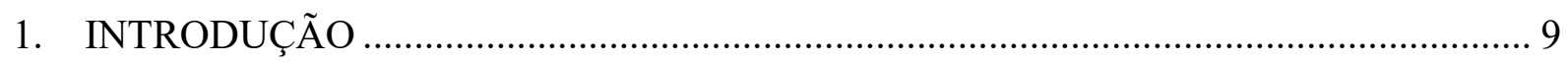

1.1.A relevância do tema para o cenário brasileiro ............................................................... 9

1.2.Políticas públicas: por uma visão jurídica abrangente ................................................ 11

1.2.1. A teoria jurídica das políticas públicas............................................ 12

1.2.2. O antitruste como política pública.................................................. 13

2. COMPLIANCE ANTITRUSTE: PRINCIPAIS CONSIDERAÇÕES PARA UM PROGRAMA EFICIENTE.

2.1.O surgimento do compliance: a governança corporativa............................................. 19

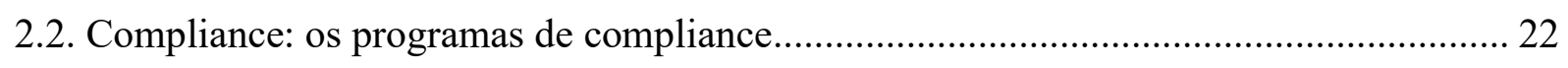

2.2.1 Aspectos comuns de um programa de compliance eficiente................... 23

2.2.2. Os princípios do Comitê da Basiléia para a função de compliance ......... 25

2.3. Programas de compliance antitruste: principais aspectos ........................................... 28

2.3.1. Programas de compliance antitruste: considerações do Conselho Administrativo

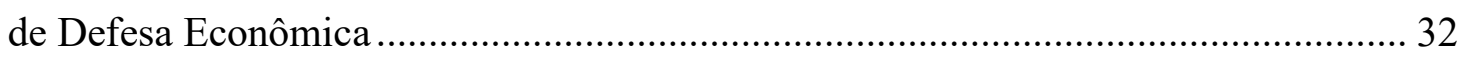

2.4. O risco antitruste: consequências do "não compliance" e da prática de cartel ................ 35

2.4.1. O cartel como crime na legislação brasileira: consequências da criminalização para as organizações e seus colaboradores.

2.5. Conclusões preliminares sobre os programas de compliance …................................... 53

3. CARTEIS EM LICITAÇÃO: PRINCIPAIS CONSIDERAÇÕES SOBRE COLUSÃO EM

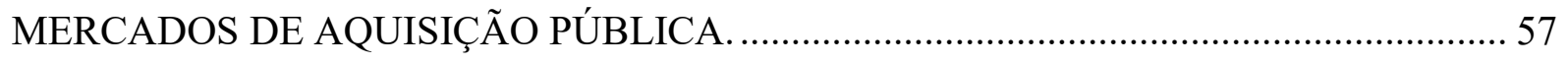

3.1. O cartel como infração antitruste: breves considerações .............................................. 57

3.1.1 O cartel tentado como infração punível ................................................... 64 
3.2. Licitações públicas como mercados propensos à colusão 66

3.2.1. Mercados propensos à colusão e suas principais características ............. 66

3.2.2. As características dos mercados de licitações públicas ......................... 71

3.2.3. Cartel em licitações como um risco provável....................................... 77

3.3. Carteis em licitação: tipologia das práticas colusivas e análise da jurisprudência do CADE 79

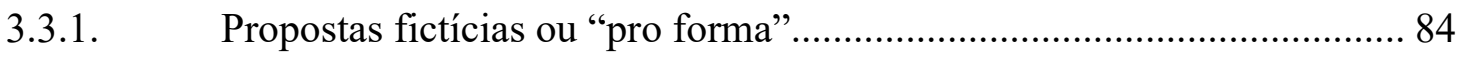

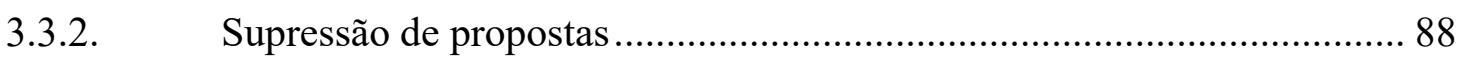

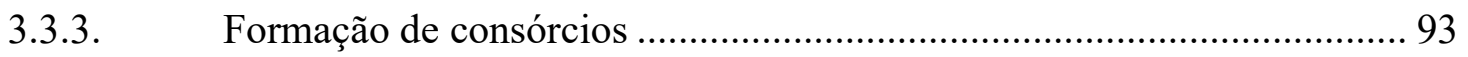

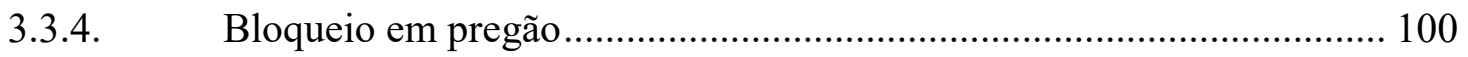

3.3.5. Rodízio de propostas e subcontratação................................................. 105

3.3.6. Outros métodos identificados na jurisprudência ................................... 112

3.4. Conclusões preliminares sobre a prática de cartel em licitações .................................... 114

4. PREVENÇÃO DE CARTÉIS EM LICITAÇÃO: DESENHANDO UM PROGRAMA DE

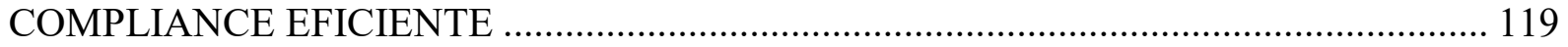

4.1. Prevenção e detecção: propostas fictícias..................................................................... 120

4.2. Prevenção e detecção: supressão de propostas .............................................................. 123

4.3. Prevenção e detecção: consórcios com propósitos anticompetitivos.............................. 124

4.4. Prevenção e detecção: bloqueio em pregão presencial ................................................ 126

4.5. Prevenção e detecção: subcontratação e rodízio de propostas ....................................... 127

4.6. Prevenção e detecção: outros métodos de conluio....................................................... 130

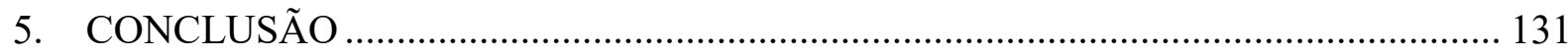

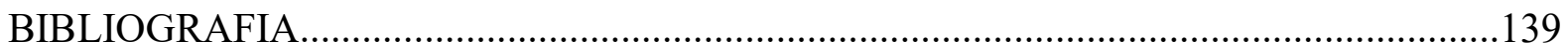

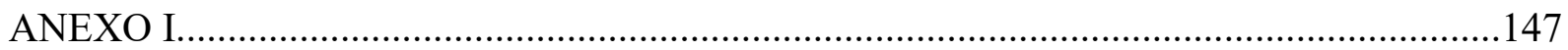




\section{INTRODUÇÃO}

\subsection{A relevância do tema para o cenário brasileiro - o direito concorrencial como política pública}

Embora os primeiros dispositivos legais relacionados à disciplina concorrencial no Brasil sejam anteriores aos anos 1950, é inegável que o direito antitruste nacional adquiriu maturidade após a promulgação da Lei no 8.884 de 1994, que permaneceu em vigor até o ano de 2012, quando entrou em vigência a Lei no 12.529 de 2011.

Nesse período, houve a ampliação significativa da atuação do Conselho Administrativo de Defesa Econômica - CADE, com o crescimento gradual do número de investigações relacionadas à prática de infrações antitruste, assim como a instituição de um programa de leniência robusto, tudo a favorecer a deteç̧ão e investigação de condutas colusivas.

Mais recentemente, a palavra "cartel” ganhou destaque nos noticiários nacionais, quando comumente esteve associada a práticas de corrupção na Administração Pública, em especial no âmbito das investigações realizadas pela denominada "Operação Lava Jato" e seus respectivos desdobramentos. Ressalvadas as inúmeras críticas existentes aos métodos de condução de tais procedimentos investigatórios, há que se reconhecer um aumento da consciência acerca dos delitos econômicos, bem como de suas consequências aos cofres públicos. Em sentido semelhante, pode-se mencionar que os agentes econômicos passam a perceber a extensão dos riscos a que estão sujeitos quando decidem tomar parte de condutas ilícitas, assim como a gravidade das sanções aplicáveis.

Neste contexto, este trabalho se propõe a um objetivo central: delinear os principais métodos que podem ser adotados por uma organização atuante em mercados de licitação pública para a prevenção e detecção de infrações antitruste, em especial o cartel. 
$\mathrm{Na}$ busca de tais parâmetros, inicia-se a presente dissertação com a consolidação do valor concorrência como parte de uma política pública, evidenciando-se a sua relevância em termos legislativos e éticos, bem como a total aplicabilidade da normativa antitruste aos projetos e obras capitaneados pelo Poder Público, que não possuem qualquer isenção relativa à legislação concorrencial.

Em um segundo momento, pretende-se analisar a função de compliance ${ }^{1}$, bem como as principais características relacionadas a um programa eficiente de boas práticas, estabelecendo-se os achados comuns da literatura. No mesmo capítulo, observam-se os principais riscos atinentes à formação de cartéis, e as consequências de tal ilícito antitruste para seus integrantes, nas esferas criminal, administrativa e cível.

Superadas tais considerações preliminares, verificam-se as principais características dos mercados de licitação pública, considerando-se as razões pelas quais tais mercados são mais suscetíveis às práticas colusivas do que os mercados típicos ou comuns, para os quais a licitação não é utilizada como sistema de contratação. Após, a partir da análise dos diversos casos julgados pelo Conselho Administrativo de Defesa Econômica, pretende-se uma análise sistemática das principais tipologias colusivas adotadas pelos cartéis em licitação, bem como a prevalência deste ou daquele método.

Assim, o quarto capítulo dedica-se integralmente ao objetivo central desta dissertação: a definição de parâmetros a serem observados por um programa de compliance dedicado à prevenção de cartéis em certames públicos, estabelecendo quais políticas e padrões podem ser adotados por uma organização para prevenir a formação de cartéis em licitação, bem como para detectá-los.

Pretende-se, portanto, que ao fim desta obra, o leitor esteja familiarizado com a disciplina dos cartéis em licitação, bem como encontre ferramentas que lhe possibilitem a

\footnotetext{
${ }^{1}$ Embora o termo "compliance" derive da língua inglesa, não constando do Vocabulário Ortográfico da Língua Portuguesa - VOLP opta-se, ao longo deste trabalho, pela grafia do termo sem a utilização do itálico, a fim de facilitar a leitura e compreensão do texto.
} 
identificação do ilícito antitruste em certames públicos, ou lhe auxiliem na tomada de decisões adequadas à disciplina concorrencial.

\subsection{Políticas públicas: por uma visão jurídica abrangente}

O termo "política pública", embora amplamente utilizado por autores e juristas, não costuma ser alvo de caracterização específica, tampouco de uma disciplina jurídica própria. De modo diverso, o termo é alvo de análises profundas por autores de outras áreas, especialmente das ciências sociais, que têm se dedicado a avaliar aspectos específicos das políticas públicas.

A despeito da diversidade de teorias existentes sobre o tema, pode-se afirmar que a definição de Marques é exemplo relevante da caracterização das políticas públicas pelos autores de ciência política: estas seriam o conjunto de ações implementadas pelo Estado e autoridades governamentais em sentido amplo ${ }^{2}$. De modo geral, a análise sistematizada de certa política sempre deve ser capaz de responder, com clareza, duas questões principais: o problema endereçado pela política em questão e o resultado que se pretende alcançar ${ }^{3}$.

Do ponto de vista jurídico, não é difícil formular críticas à definição de Marques. Em razão do seu caráter amplo, os mais diversos elementos podem ser agrupados sob o título de política pública, desconsiderando-se aspectos legais tais como a competência do ente estatal que a implementa ou a forma de instituição da política. No limite, coisas tão distintas quanto um plano nacional de redução da pobreza e uma propaganda municipal que incentive a coleta seletiva seriam elencadas e estudadas de forma conjunta, de acordo com a definição de Marques.

Como contraponto, Lowi desenvolve uma teoria de políticas públicas mais adequada ao contexto jurídico. Segundo o autor, as políticas públicas, definidas como a coerção estatal

2 MARQUES, Eduardo. As políticas públicas na Ciência Política in A Política Pública como Campo Multidisciplinar (Eduardo Marques e Carlos Aurélio Pimenta de Faria, orgs) São Paulo: Editora UNESP/Editora Fiocruz, 2013, pp. 23.

${ }^{3}$ Idem, pp. 23. 
deliberada para a adoção de um comportamento específico, poderiam ser agrupadas em quatro segmentos: (i) políticas constitutivas, associadas à criação e transformação das regras do jogo político, com potencial impacto na distribuição de recursos; (ii) políticas regulatórias, que estabeleceriam regras para o funcionamento de atividades externas ao Estado; (iii) políticas distributivas, que envolveriam a distribuição de recursos não finitos; (iv) políticas redistributivas que, por sua vez, envolveriam a distribuição de recursos finitos ou limitados ${ }^{4}$.

Tal segmentação, entretanto, não é capaz de sanar as dúvidas formuladas por um estudioso do Direito. A estrutura normativa da política, sua legitimidade e legalidade frente ao sistema vigente e sua aplicabilidade em longo prazo permanecem não caracterizadas. Neste sentido, alguns autores têm dedicado seus esforços à formulação de uma teoria jurídica das políticas públicas, cujos contornos serão delineados a seguir.

\subsubsection{A teoria jurídica das políticas públicas}

O princípio da legalidade, basilar do Estado de Direito, prevê, na sua concepção administrativa, que ao Estado não é dado fazer senão o quanto previsto em lei ${ }^{5}$. Não é difícil perceber que, sendo as políticas públicas compostas por atos governamentais, sua concepção e implementação deverá basear-se no sistema legal. A necessidade de uma análise jurídica das políticas públicas torna-se, então, bastante clara.

A Constituição Federal de 1988 consagra uma série de direitos e garantias sociais cuja consecução depende de uma ação positiva do Estado. A disciplina das políticas públicas ganha, então, força: passa-se a questionar qual é o papel do ente governamental na criação e organização dos direitos sociais, bem como no cumprimento dos objetivos constitucionais. Comparato afirma que as ações governamentais de políticas públicas devem,

\footnotetext{
${ }^{4}$ LOWI, Theodore. Four Systems of policy, politics and choice. Public Administration Review, Vol. 32, No. 4. (Jul. - Aug., 1972), pp. 298-310. Disponível em http://links.jstor.org/sici?sici=0033$3352 \% 28197207 \% 2 F 08 \% 2932 \% 3 A 4 \% 3 C 298 \% 3 A F S O P P A \% 3 E 2.0 . C O \% 3 B 2-X$

5 DI PIETRO, Maria Syvia Zanela. Da constitucionalização do direito administrativo - Reflexos sobre o princípio da legalidade e a discricionariedade administrativa. Revista do Conselho Federal da Ordem dos Advogados do Brasil - OAB. Belo Horizonte, ano 2, n. 2, jan. / jun. 2012, pp. 3-4.
} 
necessariamente, estar de acordo com o texto constitucional, não existindo qualquer espécie de "isenção" quanto ao tema. O autor advoga ainda pelo controle judicial das normas estruturantes de programas governamentais, excluindo a antiga concepção de que atos de governo ou atos políticos não estariam sujeitos ao controle dos tribunais ${ }^{6}$. Constata-se que, para Comparato, "a política aparece, antes de tudo, como uma atividade, isto é, um conjunto organizado de normas e atos tendentes à realização de um objetivo determinado".

A partir das considerações de Comparato, Dallari Bucci desenvolveu alguns parâmetros para a análise jurídica de uma política pública. Como marco inicial, a autora propõe que uma política pública é o programa de ação governamental que resulta de um processo ou conjunto de processos juridicamente regulados visando coordenar os meios à disposição do Estado e as atividades privadas, para a realização de objetivos socialmente relevantes e politicamente determinados ${ }^{7}$.

Por fim, em um contexto mais afeto à disciplina do direito econômico, Bercovicci ${ }^{8}$ considera que o fundamento das políticas públicas é a necessidade de concretização de direitos por meio de prestações positivas do Estado, sendo o desenvolvimento nacional a principal política pública. O objetivo nacional é sintetizado no desenvolvimento econômico e social, ou a superação do subdesenvolvimento, o qual depende de uma política de longo prazo que abranja diferentes setores da vida social. A partir destas considerações, o autor advoga pela retomada da atividade de planejamento econômico, como forma de ação coordenada do Estado na transformação das estruturas mantenedoras do subdesenvolvimento.

\subsubsection{O antitruste como política pública}

\footnotetext{
${ }^{6}$ COMPARATO, Fábio Konder. Ensaio sobre o juízo de constitucionalidade de políticas públicas. Revista de Informação Legislativa. Brasília a. 35 n. 138 abr./jun. 1998, pp. 39-48.

${ }^{7}$ BUCCI, Maria Paula Dallari. $O$ conceito de política pública em direito. in Políticas Públicas: Reflexões sobre o Conceito Jurídico (Maria Paula Dallari Bucci, org.) São Paulo: Saraiva, 2006, pp. 39.

${ }^{8}$ BERCOVICI, Gilberto. Planejamento e políticas públicas: por uma nova compreensão do papel do Estado in Políticas Públicas: Reflexões sobre o Conceito Jurídico. São Paulo: Saraiva, 2006, pp. 143-161.
} 
Conforme exposto nos pontos 1.2.1 e 1.2.2, a definição do termo política pública não é estática, variando de acordo com a concepção adotada. Ainda que, em linhas gerais, política pública possa ser definida como a ação estatal coordenada com objetivo determinado, opta-se por utilizar, neste trabalho, a definição proposta por Dallari Bucci, em razão da incorporação de elementos próprios da análise jurídica.

Destaca-se, ainda, que a avaliação do direito antitruste como política pública deve considerar o conceito de política da concorrência proposto por Goldberg 9 . Para o autor, a política da concorrência é composta pela junção (i) da prática das autoridades administrativas e judiciais que interpretam e aplicam o conjunto de normas vigentes, conferindo um caráter dinâmico às regras antitruste; (ii) a edição de normas em abstrato que tenham impacto sobre mercados livres ou regulados; (iii) os critérios governamentais que pautam a alocação de recursos a uma ou outra prioridade sobre as quais, discricionariamente, podem dispor qualquer autoridade de concorrência.

A fim de facilitar a avaliação do tema, e nos termos sugeridos pela autora, a proposição de Dallari Bucci poderá ser recortada em três aspectos específicos. São eles: (i) a existência de um programa governamental resultante de processos jurídicos; (ii) a coordenação, pelo programa, dos meios à disposição do Estado e das atividades privadas; (iii) a existência de um objetivo determinado a ser atingido pelo programa.

Em relação ao primeiro aspecto, parece bastante claro que a política antitruste pode ser definida como um programa governamental resultante de processos jurídicos determinados. A estrutura da política de defesa da concorrência no Brasil foi definida por uma ação estatal específica, qual seja, a promulgação da legislação concorrencial assentada na disposição constitucional de que a livre concorrência é um dos pilares da ordem econômica. Tal norma é fruto de processo legislativo federal, juridicamente regulado.

O segundo aspecto, por sua vez, também parece preenchido. A legislação concorrencial organiza e coordena meios estatais para a consolidação do programa, bem como

${ }^{9}$ GOLDBERG, Daniel K. Poder de compra e política antitruste. (Doutorado) Faculdade de Direito, Universidade de São Paulo, 2006, pp. 7. 
incentiva ou determina a participação dos agentes privados. O Conselho Administrativo de Defesa Econômica - CADE é uma autarquia federal ligada ao Ministério da Justiça, de sorte que está subordinado, em última análise, ao governo federal. Ao mesmo tempo, o CADE também conta com um elevado grau de institucionalização e independência funcional, tendo permanecido em funcionamento durante diferentes gestões governamentais. A atuação dos agentes privados, por sua vez, poderá ser facultativa, como no caso da formulação de consultas ou oferecimento de representações por infração à ordem econômica, ou obrigatória, como nos casos de notificação de atos de concentração e fornecimento de informações solicitadas pela autoridade, estando o descumprimento destes deveres sujeito às penalidades previstas em lei.

Já em relação ao terceiro aspecto - a existência de um objetivo determinado a ser atingido pelo programa - o tema parece suscitar maiores controvérsias doutrinárias.

Uma avaliação inicial poderia considerar apenas os objetivos expressamente enumerados pela legislação concorrencial em vigor. Neste sentido, o artigo $1^{\circ}$ da Lei $n^{\circ}$ 12.529 de 2011 prevê que a legislação disporá sobre a organização do Sistema Brasileiro de Defesa da Concorrência, objetivando a prevenção e a repressão às infrações contra a ordem econômica. A busca de tal desígnio seria orientada pelas previsões constitucionais de liberdade de iniciativa, livre concorrência, função social da propriedade, defesa dos consumidores e repressão ao abuso do poder econômico. Em outras palavras, o objetivo da legislação concorrencial seria a proteção da concorrência como valor em si.

Considerar, entretanto, tal disposição como resposta definitiva à indagação ora sugerida parece contrariar o longo debate doutrinário sobre o tema e o próprio histórico da legislação concorrencial. Primeiramente, deve-se lembrar que, conforme explicitado por Comparato, o objetivo de qualquer política pública deve ser compatível com as disposições 
constitucionais sobre o assunto ${ }^{10}$. Sendo assim, as disposições da Lei $\mathrm{n}^{\mathrm{o}} 12.529$ de 2011 devem ser lidas em conjunto com a previsão do artigo 170 da Constituição Federal ${ }^{11}$.

Vê-se que a livre concorrência surge como um princípio da ordem econômica, a qual deverá "assegurar a todos a existência digna, conforme os ditames da justiça social" respeitando a manutenção da livre concorrência. Para Forgioni, o texto constitucional é claro quanto ao fato de que a concorrência, na ordem jurídica brasileira, é instrumento para o alcance de um "bem maior": a justiça social ${ }^{12}$.

Existe intenso debate doutrinário acerca da finalidade da política concorrencial: se está é a mera busca da eficiência econômica ou passa pela concretização de valores constitucionalmente previstos - caso em que poderá se debater a adequação dos meios existentes para a consecução de tais objetivos. Tal discussão possui raízes históricas e terá acepções que variam conforme o sistema legal e período analisados.

Isso porque a legislação antitruste brasileira traz, em diversos momentos, o conceito de eficiência como parâmetro de análise. Para o artigo 36 da Lei no 12.529 de $2011^{13}$, a eficiência surge como excludente absoluta da ilicitude: o poder de mercado, por maior que seja, não será considerado ilícito quando adquirido em função de ganho de eficiência. Já no tópico das concentrações econômicas, a eficiência será excludente relativa da ilicitude, podendo justificar a aprovação de uma operação quando presentes os fatores determinados em lei ${ }^{14}$.

${ }^{10}$ COMPARATO, Fábio Konder. Ensaio sobre o juízo de constitucionalidade de políticas públicas. Revista de Informação Legislativa. Brasília a. 35 n. 138 abr./jun. 1998, pp. 39-48.

11 “Art. 170. A ordem econômica, fundada na valorização do trabalho humano e na livre iniciativa, tem por fim assegurar a todos existência digna, conforme os ditames da justiça social, observados os seguintes princípios:

(...)

IV - livre concorrência;”.

${ }^{12}$ FORGIONI, Paula A.. Os fundamentos do antitruste. São Paulo: Revista dos Tribunais, 2012, p. 186.

${ }^{13}$ Lei no 12.529 de 2011; Art. 36: Constituem infração da ordem econômica, independentemente de culpa, os atos sob qualquer forma manifestados, que tenham por objeto ou possam produzir os seguintes efeitos, ainda que não sejam alcançados:

(...)

$\S 1^{\underline{o}}$ A conquista de mercado resultante de processo natural fundado na maior eficiência de agente econômico em relação a seus competidores não caracteriza o ilícito previsto no inciso II do caput deste artigo.

${ }^{14}$ SALOMÃO FILHO, Calixto. Direito Concorrencial. São Paulo: Malheiros. 2013, pp. 234. 
Neste sentido, não é difícil que um intérprete perca de vista qualquer outro objetivo que, porventura, fundamente a política antitruste. A eficiência não é apenas disposição legal, mas também argumento frequentemente trazido pelas partes em concentrações econômicas, bem como fundamento das decisões exaradas pela autoridade administrativa. Este fato, para Salomão Filho, teria retirado a densidade teórica das discussões antitruste, cujo tratamento pelos órgãos decisórios é, usualmente, prático e casuístico, estando centrado na melhor interpretação da ideia de eficiência econômica ${ }^{15}$.

Sobre o tema, Forgioni aponta que, no Brasil, não se pode sustentar que a disciplina antitruste vise apenas a implementar a eficiência, seja ela alocativa, produtiva ou dinâmica. Em linha semelhante ao conceito europeu de concorrência instrumento, a autora entende que o sistema antitruste deverá criar e preservar, conforme a determinação constitucional, um ambiente em que as empresas possuam incentivos para competir e inovar, além de evitar que os mercados sejam dominados por agentes detentores de poder econômico ${ }^{16}$.

Detalhadamente, Ferraz Júnior leciona que a livre concorrência da qual trata a Constituição Federal baseia-se no elemento comportamental competitividade. Este elemento exigiria a desconcentração na formação de preços, baseada tanto na livre iniciativa quanto na titularidade privada dos bens de produção. Nesse sentido, a livre concorrência é tanto forma de tutela do consumidor, ao induzir a distribuição de recursos a preços mais baixos, quanto de tutela política da livre iniciativa, ao permitir que todos os agentes atinjam oportunidades equivalentes. Por fim, do ponto de vista social, a competitividade permitiria o nascimento de agentes econômicos de tamanho intermediário, garantindo uma sociedade mais equilibrada ${ }^{17}$.

Assim, a doutrina é praticamente unânime ao identificar a existência de uma ou outra finalidade na política antitruste, sendo possível verificar a presença do terceiro requisito elencado por Dallari Bucci para a configuração de uma política pública, conclusão esta que

\footnotetext{
${ }^{15}$ SALOMÃo FILHO, Calixto. Teoria crítico-estruturalista do Direito Comercial. São Paulo: Marcial Pons. 2015, pp. 233-234.

${ }^{16}$ FORGIONI, Paula. Os fundamentos do antitruste. São Paulo: Revista dos Tribunais. 2012, p. 188.

${ }^{17}$ FERRAZ JÚNIOR, Tércio Sampaio. A economia e o controle do Estado. O Estado de São Paulo em 04/06/1989.
} 
nos parece adequadamente fundamentada nas considerações da autora e nas disposições legislativas sobre o tema.

Por ora, é suficiente estabelecer que a política antitruste pode ser considerada como uma política pública ou, ao menos, como um conjunto consciente e direcionado de atos governamentais, de cuja tutela não se eximem os demais projetos titularizados pelo Poder Público. 


\section{CONCLUSÃO}

Ao longo dos quatro capítulos anteriores pretendeu-se estabelecer as premissas que demonstrariam a necessidade de que empresas atuantes em processos licitatórios desenhassem programas específicos de boas práticas, ou de compliance, voltados à prevenção e detecção de infrações antitruste, em especial os cartéis.

Em um primeiro momento, pretendeu-se determinar que a política antitruste é uma política pública com previsão constitucional, de sorte que as disposições da legislação concorrencial não podem ser ignoradas ou afastadas em qualquer hipótese, ainda que no contexto de projetos capitaneados pela Administração Pública. Embora tal conclusão pareça ser, sem certa medida, intuitiva, é inegável que há controvérsias históricas acerca de tal submissão do Poder Público às normas aplicáveis aos particulares, debates estes que vem sendo gradativamente superados com a adoção de uma visão gerencial da Administração Pública.

Há de se observar que os dispositivos próprios da legislação antitruste, grandemente pautada pelo vetor efíciência e voltada à consecução dos princípios da ordem econômica estabelecidos constitucionalmente, não são contrários - mas absolutamente compatíveis com os princípios aplicáveis à Administração Pública, de sorte que é perfeitamente possível a sua adoção em procedimentos regidos pelas normas de Direito Público, assim como para os contratos administrativos firmados sob tal égide.

Superadas tais considerações preliminares, observa-se que a responsabilidade corporativa surge, há mais de um século, como um dos pilares dos mecanismos de governança, em especial quanto à redução das externalidades negativas relacionadas a determinado modelo de negócios. Ainda que a rubrica "governança corporativa" abarque medidas que não estão limitadas aos programas de boas práticas, é bem estabelecido que os denominados programas de compliance compõem uma de suas diversas facetas.

Nesse sentido, "estar em compliance" corresponde à tomada de decisões corporativas que respeitem à legislação, normas e regulamentos aplicáveis às companhias, podendo englobar, mas não se limitando ao, direito antitruste. Entende-se que o cumprimento adequado das disposições legais poderá ser incentivado tanto pelo temor de sanções diretamente 
aplicáveis àqueles que os descumprirem, quanto pela ocorrência de prejuízos indiretos, como a menor possibilidade de captação de recursos no mercado de capitais por companhias que se encontrem sob investigação ou que tenham sido alvo de sanções aplicadas pelas autoridades públicas.

Assim, o "risco de compliance" pode ser entendido sob duas óticas distintas, às quais se pretendeu abordar ao longo dos capítulos 2 e 3 deste trabalho: a probabilidade de ocorrência do fato e a gravidade de suas consequências.

A partir desta divisão, estabeleceu-se que os cartéis são atos ilícitos e os agentes participantes do conluio, sejam pessoas físicas ou jurídicas, estão sujeitos à responsabilização nas esferas administrativa e criminal. Admitiu-se que embora a possibilidade de encarceramento para os indivíduos envolvidos na prática de cartel seja baixa, em especial diante da quantidade de pena cominada ao delito em questão, esta não é desprezível. Por outro lado, a criminalização da conduta de cartel é medida que traz consequências processuais importantes na legislação brasileira, em especial a possibilidade de utilização de interceptações telefônicas ao longo das investigações, assim como a significativa dilação do prazo prescricional da conduta.

Aliadas às sanções pecuniárias e corporais, avaliou-se que empresas condenadas pela prática de cartel em licitações podem ser impedidas de contratar novamente com o Poder Público, verificando-se que tal sanção foi imposta em parcela significativa dos casos julgados pelo CADE. Não bastasse, as companhias ainda encontra-se sujeitas às medidas de natureza cível, em especial a reparação dos danos causados pela conduta.

Em relação à probabilidade de detecção dos cartéis, considerou-se ainda que a existência de um programa de leniência é fator que desestabiliza o acordo firmado, elevando as chances de detecção do conluio, eis que seus integrantes possuem um relevante incentivo para reportarem os fatos às autoridades competentes. Verificou-se ainda que os requisitos para a imposição de sanções administrativas pelo CADE são razoavelmente elásticos, até mesmo porque o cartel é considerado um ilícito pelo objeto, de sorte que é desnecessária a comprovação dos efeitos do acordo, bastando que se demonstre a sua ocorrência, ainda que na modalidade tentada. 
Em outras palavras, o participante de um cartel vê-se em um ambiente instável, em que há incentivos para a traição pelos demais membros do conluio, estando sujeito à aplicação de sanções múltiplas, podendo a autoridade pública valer-se de métodos de investigação próprios das infrações criminais, muito embora os parâmetros de prova sejam mais flexíveis do que os convencionados pela lei penal.

Ao lado da gravidade das consequências relacionadas à prática do cartel, tem-se que os mercados de aquisição pública são especialmente suscetíveis à ocorrência de condutas colusivas, posto que apresentam características relacionadas à maior probabilidade, estabilidade e duração destes acordos ilícitos.

Observa-se que o procedimento licitatório é um método específico de contratação, e não há correlação direta com os bens, produtos ou serviços ofertados, mas sim com o procedimento adotado para a formação da relação negocial. Entretanto, o regramento deste sistema de contratação, notadamente trazido pela Lei $n^{\circ} 8.666$ de 1993, favorece a formação de cartéis ao estabelecer parâmetros elevados de transparência das informações, assim como ao dar preferência à competição baseada no critério preço.

Em comparação aos mercados típicos, os agentes dedicados à formação do cartel em licitação contarão com duas vantagens: a possibilidade de coordenação dos preços e condições de venda, assim como a quase perfeita fiscalização do cumprimento do acordo, criando condições praticamente ideais para a realização do conluio. Soma-se a isso o fato de que procedimentos licitatórios são realizados em períodos temporais pré-determinados, e muitas vezes ocorrem em contextos de "múltiplos jogos" - em um cenário de jogos múltiplos e repetidos, não apenas se ampliam as oportunidades de cooperação, que serão tão elevadas quanto o número de jogadas, mas também se permite a adequação das estratégias dos jogadores, que poderão refletir, a cada movimento, sobre as jogadas passadas de seus adversários, adaptando os métodos cooperativos anteriormente definidos.

Ultrapassadas tais considerações, passou-se a análise dos métodos usualmente empregados pelos cartéis em licitação para a divisão do respectivo mercado, verificando-se em que medida tais métodos aproximam-se ou afastam-se daqueles empregados pelos agentes que atuam em mercados típicos. A partir da análise dos casos julgados e investigados pelo Conselho Administrativo de Defesa Econômica, pode se verificar a prevalência de algumas 
tipologias colusivas, incluindo a apresentação de propostas fictícias, a supressão de propostas, a desistência de propostas apresentadas, a formação de consórcios, a subcontratação de concorrentes e o bloqueio em pregões presenciais.

O estudo sistematizado destes casos permitiu a categorização das estratégias colusivas em dois blocos distintos, aos quais se denominou de "métodos de fraude", que são voltados à manipulação do resultado em um certame específico, e "métodos de divisão", que possibilitam a divisão dos mercados de licitações públicas. Em grande parte dos procedimentos administrativos analisados houve o emprego conjunto de "métodos de fraude", que permitiram aos participantes do conluio definirem previamente quem seria o vencedor da licitação, e de "métodos de divisão", que possibilitaram a compensação financeira dos licitantes perdedores, seja por meio da adjudicação de uma parte do objeto contratado, seja pela obtenção de outros contratos administrativos.

Assim, entende-se que essa dissertação pode validar uma das principais premissas apontadas pela doutrina como relacionadas a um programa de compliance eficiente - a necessidade de adequação do programa à área da atuação da companhia, com a identificação dos riscos específicos à atividade desempenhada, mensuração destes riscos e elaboração de medidas adequadas à sua prevenção.

Portanto, o caráter único dos procedimentos licitatórios, nos termos da legislação em vigor, os transformam em mercados singulares, de sorte que programas de compliance antitruste de cunho genérico talvez não sejam suficientes ou adequados à prevenção e detecção dos cartéis em licitação.

Deste modo, e consideradas todas estas premissas, o capítulo 4 foi dedicado à análise dos principais sinais de ocorrência de conluio, a teor das tipologias anteriormente definidas, bem como ao estabelecimento de "salvaguardas" aos gestores de organizações que, desejando participar de procedimentos licitatórios, pretendam se assegurar da licitude de suas condutas. Nesse contexto, despontou a necessidade de documentação adequada dos vetores que levaram à tomada de certa decisão negocial, ao que se pode chamar de "cadeia de decisão".

Isto porque os métodos colusivos aplicáveis aos procedimentos licitatórios muitas vezes se revestem de uma aparência de licitude e, nesse sentido, nenhum exemplo é mais 
emblemático do que a formação de consórcios. A formação de parcerias entre empresas é incentivada pela legislação de licitações, e também pela jurisprudência do Tribunal de Contas da União, inexistindo qualquer vedação à criação de consórcios entre empresas concorrentes ou ainda a limitação de agentes integrantes de tal arranjo. Por outro lado, um consórcio entre empresas competidoras, associadas para a participação em um mesmo projeto, parece contrariar frontalmente os princípios da legislação antitruste, reduzindo artificialmente o número de concorrentes do procedimento licitatório.

Assim, é indispensável que sejam avaliadas as razões que levaram à formação de consórcio, a fim de que se verifique a sua licitude do ponto de vista concorrencial. No limite, um consórcio formado apenas para que as participantes da licitação dividam entre si o escopo do projeto, sem qualquer fundamento de ordem técnica ou econômica, nada mais é do que um cartel. 


\section{BIBLIOGRAFIA}

ABRANTES-METZ, Rosa M., SOKOL, Daniel. Antitrust Corporate Governance and Compliance (April 8, 2013). Oxford Handbook of International Antitrust Economics, Roger D. Blair and D. Daniel Sokol, eds., Oxford University Press, Forthcoming; Minnesota Legal Studies Research Paper No. 13-18.

ACC - Australian Competition and Consumer Comission. Bid rigging. Disponível em https://www.accc.gov.au/business/anti-competitive-behaviour/cartels/bid-rigging.

ALMEIDA, Fernando Dias Menezes de. Contratos administrativos. Direito dos contratos II. São Paulo: Quartier Latin, 2008.

AMARAL, Antonio Carlos Cintra. Ato administrativo, licitações e contratos administrativos. São Paulo: Malheiros, 1995.

ANAND, Anita. Voluntary vs. Mandatory Corporate Governance: towards an optimal regulatory framework. American Law \& Economics Association - Annual Meeting 2005. New Haven: Yale Law School, 2005.

BAIN, Jon. Barriers to new competition. Harvard University Press, 1956.

BAINBRIDGE, Stephen. Caremark and Enterprise Risk Management. 2009. UCLA School of Law, Law-Econ Research Paper No. 09-08.

BAKER, Donald. Deterring Cartels - The Criminalization Dimension. 2011.

BANDEIRA DE MELlo, Celso Antônio. Curso de Direito Administrativo. São Paulo: Malheiros. 27 Edição. 2010.

BAXTER, Thomas C.; The Changing Face of Corporate Compliance and Corporate Governance, 21 Fordham J. Corp. \& Fin. L. 1 (2016).

BERCOVICI, Gilberto. Planejamento e políticas públicas: por uma nova compreensão do papel do Estado in Políticas Públicas: Reflexões sobre o Conceito Jurídico. São Paulo: Saraiva, 2006. 
BERGMAN, Howard, e SOKOL, D. Daniel, The Air Cargo Cartel: Lessons for Compliance (September 29, 2014).

BERLE, Adolf e MEANS, Gardiner. A moderna sociedade anônima e a propriedade privada. São Paulo: Abril Cultural, 1984.

BUCCI, Maria Paula Dallari. O conceito de política pública em direito. in Políticas Públicas: Reflexões sobre o Conceito Jurídico (Maria Paula Dallari Bucci, org.) São Paulo: Saraiva, 2006.

CARVALHO, Vinicíus Marques., CORDOVIL, Leonor; BAGNOLI, Vicente; ANDERS, Eduardo Caminati. Nova Lei de Defesa da Concorrência Comentada. São Paulo: Revista dos Tribunais, 2011.

CARVALHO, Vinicíus Marques. MENDES, Francisco. Compliance: concorrência e combate à corrupção. São Paulo: Trevisan, 2017.

CASELTA, Daniel Costa. Responsabilidade civil por danos decorrentes da prática de cartel. Dissertação de Mestrado. Faculdade de Direito da Universidade de São Paulo.

CECCATO, Marco Aurélio. Cartéis em licitações: estudo tipológico das práticas colusivas entre licitantes e mecanismos extrajudiciais de combate. 2012. Disponível em http://seae.fazenda.gov.br/premio-seae/edicoes-anteriores/edicao-2012/vii-premio-seae.

COMMITTEE OF SPONSORING ORGANISATIONS OF THE TREADWAY COMMISSION. Internal Control - Integrated Framework. $6^{\mathrm{a}}$ Edição. Disponível em http://www.coso.org/documents/coso_framework body_v6.pdf.

COMITÉ DA BASILÉIA PARA SUPERVISÃO DA ATIVIDADE BANCÁRIA. Compliance and the compliance function in banks. Disponível em http://www.bis.org/publ/bcbs113.pdf.

COMPARATO, Fábio Konder. Ensaio sobre o juízo de constitucionalidade de políticas públicas. Revista de Informação Legislativa. Brasília a. 35 n. 138 abr./jun. 1998.

CONNOR, John M. and Lande, Robert H., Cartels as Rational Business Strategy: Crime Pays (November 1, 2012). 34 Cardozo Law Review 427 (2012). 
CADE - Conselho Administrativo De Defesa Econômica. Guia para programas de compliance. 2016. Disponível em http://www.cade.gov.br/acesso-a-informacao/publicacoesinstitucionais/guias_do_Cade/guia-compliance-versao oficial.pdf.

CADE - Conselho Administrativo De Defesa Econômica. Inquérito Administrativo sigiloso 08700.006377/2016-62, em trâmite.

CADE - Conselho Administrativo De Defesa Econômica. Processo Administrativo 08012.009382/2010- $\neg 90$ ("Cartel das Construtoras de Curitiba"), julgado em 22 de junho de 2017.

CADE - Conselho Administrativo De Defesa Econômica. Processo Administrativo 08012. 003321/2004-71 (“Cartel dos Hemoderivados”), julgado em 13 de abril de 2016.

CADE - Conselho Administrativo De Defesa Econômica. Processo Administrativo 08012.008850/2008-94 (“Cartel das Lavanderias Hospitalares”), julgado em 03 de fevereiro de 2016.

CADE - Conselho Administrativo De Defesa Econômica. Processo Administrativo 08012.008821/2008-22 (“Cartel dos medicamentos antirretrovirais"), julgado em 20 de janeiro de 2016.

CADE - Conselho Administrativo De Defesa Econômica. Processo Administrativo 08012.001273/2010-24 (“Cartel dos aquecedores solares”), julgado em 16 de setembro de 2015.

CADE - Conselho Administrativo De Defesa Econômica. Processo Administrativo 08012.009885/2009-21 (“Cartel dos Mambu Branco”), julgado em 08 de abril de 2015.

CADE - Conselho Administrativo De Defesa Econômica. Processo Administrativo 08012.008184/2011-90, julgado em 08 de abril de 2015.

CADE - Conselho Administrativo De Defesa Econômica. Processo Administrativo 08012.008507/2004-16 (“Cartel das Órteses e Próteses”), julgado em 10 de dezembro de 2014. 
CADE - Conselho Administrativo De Defesa Econômica. Processo Administrativo 08012.009611/2008-51 (“Cartel dos Detectores de Metais”), julgado em 10 de dezembro de 2014.

CADE - Conselho Administrativo De Defesa Econômica. Processo Administrativo 08012.006199/2009-07, julgado em 10 de dezembro de 2014.

CADE - Conselho Administrativo De Defesa Econômica. Processo Administrativo 08012.011853/2008-13, julgado em 05 de fevereiro de 2014.

CADE - Conselho Administrativo De Defesa Econômica. Processo Administrativo 08012.010362/2007-66 (“Cartel do Transporte Aéreo”), julgado em 29 de junho de 2015.

CADE - Conselho Administrativo De Defesa Econômica. Processo Administrativo 08012.001826/2003-10 (“Cartel dos Vigilantes”), julgado em 04 de abril de 2007.

CADE - Conselho Administrativo De Defesa Econômica. Processo Administrativo 08012.006989/1997-43, julgado em 15 de junho de 2005 .

CADE - Conselho Administrativo De Defesa Econômica. Processo Administrativo 08012.009118/1998-26, julgado em 27 de junho de 2001.

CADE - Conselho Administrativo De Defesa Econômica. Processo Administrativo $\mathrm{n}^{\circ}$ 08012.008184/2011-90, em trâmite.

CADE - Conselho Administrativo De Defesa Econômica. Processo Administrativo $\mathrm{n}^{\mathrm{o}}$ 08700.004617/2013-41, em trâmite.

CADE - Conselho Administrativo De Defesa Econômica. Resolução n. 03 de 29 de maio de 2012. Disponível em http://www.cade.gov.br/assuntos/normas-elegislacao/resolucao/resolucao-3 2012-ramos-atividade.pdf/view.

DELOITTE. Compliance Trends Survey. 2014. Disponível em http://www2.deloitte.com/content/dam/Deloitte/us/Documents/risk/us_aers_dcrs_deloitte_co mpliance_week_c mpliance_survey_2014_05142014.pdf. .

DE PAUlA, G. M. e STANLEY, L. E. Governabilidad Corporativa em América Latina: estructura patrimonial, prácticas y políticas públicas. Santiago do Chile, 2006. 
DICK, Andrew R. When Are Cartels Stable Contracts? Journal of Law and Economics, 1996, 39(1).

DI PIETRO, Maria Syvia Zanela. Da constitucionalização do direito administrativo Reflexos sobre o princípio da legalidade e a discricionariedade administrativa. Revista do Conselho Federal da Ordem dos Advogados do Brasil - OAB. Belo Horizonte, ano 2, n. 2, jan. / jun. 2012.

DI PIETRO, Maria Syvia Zanela. Direito Administrativo. São Paulo: São Paulo, 2012.

DROMI, José Roberto. La licitacion pública. Buenos Aires. Editora Astrea, 1975.

ELHAUGE, Einer; GERADIN, Damien. Global Competition Law and Economics. Oxford: Hart Publishing, 2007.

FERRAZ JÚNIOR, Tércio Sampaio. A economia e o controle do Estado. Publicado em "O Estado de São Paulo" em 04/06/1989.

FERRAZ Jr., Tércio Sampaio. Lei de defesa da concorrência: origem histórica e base constitucional. Arquivos do Ministério da Justiça. Brasília, v.45, n. 180, jul/dez, p. 175-185, 1992.

FERRAZ JUNIOR, Tercio Sampaio; SALOMÃO FILHO, Calixto; NUSDEO, Fabio (Org.). Poder Econômico: Direito, Pobreza, Violência, Corrupção. Barueri: Manole, 2009.

FINGLETON, John; GIRARD, Marie-Barbe; WILLIAMS, Simon. The fight against cartels: is a 'mixed' approach to enforcement the answer? 2011.

FORGIONI, Paula. Os fundamentos do antitruste. São Paulo: Revista dos Tribunais, 2012.

GABAN, M. Eduardo; DOMINGUES, Juliana. Direito Antitruste. São Paulo: Saraiva. 2012

GERADIN, Damien. Antitrust Compliance Programmes \& Optimal Antitrust Enforcement: A Reply to Wouter Wils (March 29, 2013). Journal of Antitrust Enforcement (2013)

GOLDBERG, Daniel K. Poder de compra e política antitruste. (Doutorado) Faculdade de Direito, Universidade de São Paulo, 2006. 
GRECO, Rogério. Curso de Direito Penal. Volume 1. $18^{\text {a }}$ Edição. Editora Impetus, São Paulo.

GRIFFITH, Sean J. Corporate Governance in an Era of Compliance. William \& Mary Law Review, Vol. 57, n. 6, 2016; Fordham Law Legal Studies.

HAY, George, e KELLEY, Daniel. An Empirical Survey of Price Fixing Conspiracies. Journal of Law and Economics, 1974.

HOVEnKamP, H. Federal Antitrust Policy: the law of competition and its practice. St. Paul: West Group, 1999.

IBGC - Instituto Brasileiro de Governança Corporativa. Código das Melhores Práticas da Governança Corporativa. 5 Edição, 2014. Disponível em http://www.ibgc.org.br/userfiles/2014/files/CMPGPT.pdf.

ICC - International Chamber of Comerce. Antitrust Compliance Toolkit. 2013. Disponível em http://www.iccwbo.org/Advocacy-Codes-and-Rules/Document-centre/2013/ICCAntitrust-Compliance-Toolkit

JENSEN, Michael e MECKLING, William. Theory of the Firm: Managerial Behavior, Agency Costs and Ownership Structure, 3 J. FIN. ECON. 305, 327 (1976).

JUSTEN FILHO, Marçal. Comentários à lei de licitações e contratos administrativos. $15^{\text {a }}$ ed. São Paulo: Dialética, 2012.

JUSTEN FILHO, Marçal. Pregão (comentários à legislação do pregão comum e eletrônico). São Paulo: Dialética, 2005.

JFDF - Justiça Federal do Distrito Federal. Ações Judiciais n ${ }^{\circ}$ 2007.34.00.043978-7; 2008.34.00.000638-5; 2007.34.00.043980-0; 2008.34.00.000496-0; 2008.34.00.000495-7; 2008.34.00.003164-2; 2008.34.00.003138-9; 2008.34.00.008656-0; 2007.34.00.044419-6; 2008.34.00.001816-7; 2008.34.00.001801-6; 2007.34.00.043979-0; 2008.34.00.000497-4; 2008.34.00.001805-0; 2008.34.00.000639-9; 2007.34.00.044314-6; 2008.34.00.002628-4; 2007.34.00.043998-2 e 2008.34.00.003133-0. Disponível para consulta em https://portal.trf1.jus.br/portaltrf1/pagina-inicial.htm. 
LACHNIT, Eva Suzanne. Compliance Programmes in Competition Law: Improving the Approach of Competition Authorities (December 12, 2014). Utrecht Law Review, Vol. 10, No. 5, p. 31-50.

LANDE, Robert H.; MARVEL, Howard. P. The three types of collusion: fixing prices, rivals and rules. Winsconsin law review. Vol. 2000.

LEVENSTEIN, Margaret C. and SUSLOW, Valerie Y., What Determines Cartel Success? Journal of Economic Literature, Vol. 44, No. 1, 2006.

LOWI, Theodore. Four Systems of policy, politics and choice. Public Administration Review, Vol. 32, No. 4. (Jul. - Aug., 1972). Disponível em http://links.jstor.org/sici?sici=00333352\%28197207\%2F08\%2932\%3A4\%3C298\%3AFSOPP $\underline{\mathrm{A} \% 3 \mathrm{E} 2.0 . \mathrm{CO} \% 3 \mathrm{~B} 2-\mathrm{X}}$

MALARD, Neide Teresinha. O Cartel. Revista de Direito Econômico, volume 21, Brasília CADE, out/dez de 1995.

MANKIW, N. Gregory. Introdução à economia. 2 ed. Rio de Janeiro. Ed. Campus,. 2001.

MARQUES, Eduardo. As políticas públicas na Ciência Política in A Política Pública como Campo Multidisciplinar (Eduardo Marques e Carlos Aurélio Pimenta de Faria, orgs) São Paulo: Editora UNESP/Editora Fiocruz, 2013.

MARQUEZ, Jaime. Life Expectancy of International Cartels: An Empirical Analysis. Review of Industrial Organization, 1994, 9(3).

MARTINEZ, Ana Paula. Repressão a cartéis: interface entre o direito administrativo e o direito criminal. Doutorado. Faculdade de Direito da Universidade de São Paulo. 2013.

MARSHAL, Roberts, e MARX, Leslie. The economics of collusion: cartels and bid riggings. MIT Press: 2014.

MEIRELlES, Hely Lopes. Licitação e Contrato Administrativo. 12 ed. São Paulo: Malheiros, 1999.

MILLER, Geoffrey. The Law Of Governance, Risk Management, And Compliance. Wolters Kluwer Law \& Business. 2014. 
MOTTA, Massimo. Competition Policy: Theory and Practice. Cambridge University Press, 2003.

OCDE - Organização para a Cooperação e Desenvolvimento Econômico. Promoting Compliance with competition law. Disponível em http://www.oecd.org/daf/competition/Promotingcompliancewithcompetitionlaw2011.pf

OECD - Organização para a Cooperação e Desenvolvimento Econômico. Relationship Between Public and Private Antitrust Enforcement, 2015. Disponível em http://www.oecd.org/daf/competition/antitrust-enforcement-in-competition.htm

OCDE - Organização para a Cooperação e Desenvolvimento Econômico. Fighting Hard Core Cartels; Harm, Effective Sanctions and Leniency Programs, 2002. Disponível em https://www.oecd.org/competition/cartels/1841891.pdf.

OCDE - Organização para a Cooperação e Desenvolvimento Econômico. Cartel Sanctions $\begin{array}{lllll}\text { against } & \text { individuals, } & 2003 . & \text { Disponível em }\end{array}$ https://www.oecd.org/competition/cartels/34306028.pdf.

OLIVEIRA, Alessandro Vinicius Marques; TUROLLA, Frederico Araújo. Combate aos Cartéis. Disponível em http://bibliotecadigital.fgv.br/ojs/index.php/gvexecutivo/article/viewFile/34079/32888.

PARKER, Christine. The Compliance Trap: The Moral Message in Responsive Regulatory Enforcement. 2006. Disponível em http://ssrn.com/abstract=927559.

PFEIFFER, Roberto Augusto Castellanos. Defesa da Concorrência e Bem-Estar do Consumidor. Revista dos Tribunais. 2015.

POSNER, Richard A. Antistrust Law. Chicago. University of Chicago, 2002.

POSNER, Richard A. Optimal Sentences for White Collar Criminals. 1980.

RIBAS, Guilherme. Programas de compliance antitruste. In: Zanotta, P.; Brancher, P. (orgs.). Desafios atuais do direito da concorrência. São Paulo: Singular, 2009.

SALOMÃO FILHO, Calixto. Direito Concorrencial. São Paulo: Malheiros. 2013. 
SALOMÃO FILHO, Calixto. Teoria crítico-estruturalista do Direito Comercial. São Paulo: Marcial Pons. 2015.

SALOMÃO FILHO, Calixto. Regulação e Concorrência. São Paulo: Malheiros. 2002.

SAMPAIO FERRAZ JR., Tércio. Direito da concorrência e enforcement privado na legislação brasileira. Revista de Direito da Concorrência. Volume 1. Novembro de 2013.

SCHUARTZ, Luiz Fernando. Ilícito antitruste e acordo entre concorrentes. Ensaios sobre economia e direito da concorrência. São Paulo: Singular, 2012.

SHAFFER, Gregory, NESBITT, Nathaniel H., WALLER, Spencer Weber. Criminalizing Cartels: A Global Trend? Minnesota Legal Studies Research Paper. 2013.

SHLEIFER, A.; VISHNY, R. W. A survey of corporate governance. Cambridge: National Bureau of Economic Research, 1996.

SOKOL, Daniel. Antitrust Corporate Governance and Compliance. University of Minnesota - Law School Legal Studies Research Paper Series Research Paper No. 13-18.

SOKOL, D. Daniel. Detection and Compliance in Cartel Policy (September 30, 2011). CPI Antitrust Chronicle, Vol. 2, September 2011.

SOKOL, D. Daniel. Cartels, Corporate Compliance and What Practitioners Really Think About Enforcement (June 6, 2012). Antitrust Law Journal, Vol. 78, 2012.

STEPHAN, Andreas. Hear no Evil, See no Evil: Why Antitrust Compliance Programmes may be Ineffective at Preventing Cartels 2009.

STIEGLER, George J. A Theory of Oligopoly. The Journal of Political Economy, Volume 72, Issue I, Fevereiro de 1964.

TRIBUNAL DE JUSTIÇA DE MINAS GERAIS. Apelação Cível n. 1.0024.07.441999-5/004 - Comarca de Belo Horizonte. Apelante(s): Sudoeste Serviços Gerais Ltda./ Apelado(a)(s): Estado de Minas Gerais - Relator: Exmo. Sr. Des. Nepomuceno Silva. Julgado em 19.02.2010. 
TCU - Tribunal de Contas da União. Licitações e Contratos: Orientações e Jurisprudência. $4^{\mathrm{a}}$

Edição. $2010 . \quad$ Disponível em

http://www.tcu.gov.br/Consultas/Juris/Docs/LIC_CONTR/2057620.PDF.

VELJANOVSK, CENTO. The economics of collusion. 2007. Disponível em https://papers.ssrn.com/sol3/papers.cfm?abstract id=975612.

VON PAPP, Florian Wagner. What If All Bid-Riggers Went To Prison and Nobody

Noticed? Criminal Antitrust Law Enforcement in Germany. 2010.

WERDEN, Gregory. Sanctioning Cartel Activity: Let the Punishment Fit the Crime. 2009.

WILLER, Ralf. Hiding a Cartel's traces - A criminal offence? A comparative review of liability for obstruction of Justice Under German, French and US Law. 2014.

WILS, Wouter. Antitrust Compliance Programmes \& Optimal Antitrust Enforcement (October 31, 2012). Journal of Antitrust Enforcement, Volume 1, Issue 1, April 2013. 
Anexo I - Processos Administrativos citados ao longo desta dissertação 


\section{Processo Administrativo $\mathrm{n}^{0}$ 08012.009382/2010-90}

Representante: Secretaria de Acompanhamento Econômico do Ministério da Fazenda.

Representadas: Afirma Consultoria e Projetos de Engenharia Ltda.; Associação Paranaense de Empresários de Obras Públicas - APEOP; CESBE S.A. Engenharia e Empreendimentos; Construtora Brasileira e Mineradora Ltda. - CBEMI; Construtora Estrutural Ltda.; Construtora Triunfo S.A.; De Amorim Construtora de Obras Ltda.; Delta Construções S.A.; EMPO - Empresa Curitibana de Saneamento e Construção Civil Ltda.; Feg Engenharia de Obras Ltda.; Gaissler Moreira Engenharia Civil Ltda.; Marc Construtora de Obras Ltda.; Redram Construtora de Obras Ltda.; Carlos Henrique Machado; Cláudio Bidóia; Emerson Gava; Fernando Afonso Gaissler Moreira; Gilberto Piva; Juarez Nassur Cordeiro; Mário Henrique Furtado de Andrade.

Relator: Conselheiro Gilvandro Vasconcelos Coelho de Araujo

Voto vista: Conselheiro Paulo Burnier da Silva.

Julgamento: 07 de junho de 2017.

Mercado: Obras de construção em vias urbanas na cidade de Curitiba.

Tipologia do Cartel: Rodízio de propostas; apresentação de propostas fictícias.

Penalidades: Sanção Pecuniária.

\section{Processo Administrativo $\mathrm{n}^{0}$ 08012.003321/2004-71}

Representante: Secretaria de Direito Econômico ex officio.

Representadas: Alpha Therapeutic Corporation; Baxter AG; Baxter Export Corporation; Baxter Hospitalar Ltda.; Bio Products Laboratory; Biotest Pharma GmbH; Cristália Produtos Químicos Farmacêuticos Ltda.; Elias Esperidião Abboadalla; Fundação do Sangue; Grifols Brasil Ltda.; Immuno Produtos Biológicos e Químicos Ltda.; Instituto Sierovaccinogeno 
Italiano S.p.A.; Itacá Laboratórios Ltda.; Jaisler Jabour de Alvarenga; Laboratoire Français du Fractionnement et Des Biotechnologies; Lourenço Rommel Ponte Peixoto; Marcos Pedrilson Produtos Hospitalares Ltda.; Marcelo Pupkin Pitta; UCB Biopharma S.A. (anteriormente denominada Meizler Comércio Internacional S.A.); Octapharma AG; Octapharma Brasil S.A.; Probitas Pharma S.A.; The American National Red Cross; United Medical Ltda.; ZLB Behring GmbH (atual denominação da Aventis Behring GmbH, anteriormente denominada Centeon $\mathrm{GmbH}$ ); ZLB Behring LLC (atual denominação da Aventis Behring LLC, anteriormente denominada Centeon LLC); CSL Behring Comércio de Produtos Farmacêuticos Ltda. (atual denominação da Aventis Behring Ltda., anteriormente denominada Centeon Farmacêutica Ltda.).

Relator: Conselheiro Gilvandro Vasconcelos Coelho de Araujo

Julgamento: 13 de abril de 2016

Mercado: Fornecimento de hemoderivados.

Tipologia do Cartel: Rodízio de propostas; apresentação de propostas fíctícias.

Penalidades: Sanção Pecuniária.

\section{Processo Administrativo $\mathrm{n}^{0}$ 08012.008850/2008-94}

Representante: Secretaria de Direito Econômico ex officio.

Representadas: Brasil Sul Indústria e Comércio Ltda.; Lógica Lavanderia e Limpeza Ltda.; Lavanderia São Sebastião de Nilópolis Ltda.; Ferlim Serviços Técnicos Ltda.; Lido Serviços Gerais Ltda.; Prolav Serviços Técnicos Ltda.; Sindicato das Empresas de Lavanderias e Similares no Rio de Janeiro - SINDILAV; Atmosfera Gestão e Higienização de Têxteis S.A.; Altineu Pires Coutinho; Marcelo Cortes Freitas Coutinho; Antônio Augusto Menezes Teixeira; Altivo Augusto Gold Bittencourt Pires; Gilberto da Silveira Côrrea; José Otávio Kudsi Macedo; Geraldo da Costa Brito; Celso Quintanilha D'Avilla; Luiz de Mello Maia Filho; Leonardo Luis Roedel Ascenção; Raphael Cortes Freitas Coutinho; Julio César Canova. 
Relator: Conselheira Ana Frazão

Julgamento: 3 de fevereiro de 2016

Mercado: Serviços de Lavanderia Hospitalar.

Tipologia do Cartel: Rodízio de propostas; apresentação de propostas fictícias.

Penalidades: Sanção pecuniária variável entre $15 \%$ a $17 \%$ do faturamento bruto anual; proibição de licitar pelo prazo de cinco anos aplicada apenas para a empresa líder do cartel e seus administradores.

\section{Processo Administrativo $n^{0} 08012.008821 / 2008-22$}

Representante: Secretaria de Direito Econômico ex officio.

Representadas: Aurobindo Farmacêutica do Brasil Ltda e AB Farmo Química Ltda., (sucedidas por Aurobindo Pharma Indústria Farmacêutica Ltda.), Brasvit Indústria e Comércio Ltda., Pharma Nostra Comercial Ltda., César Augusto Alexandre Fonseca, Daniela Bosso Fujiki, Flávio Garcia da Silva, Francisco Sampaio Vieira de Faria, José Augusto Alves Lucas, Premanandam Modapohala, Ronaldo Alexandre Fonseca e Vittorio Tedeschi.

Relator: Conselheiro Gilvandro Vasconcelos Coelho de Araújo

Julgamento: 20 de janeiro de 2016

Mercado: Fornecimento de insumos para a fabricação de medicamentos antirretrovirais.

Tipologia do Cartel: Rodízio de propostas; apresentação de propostas fictícias.

Penalidades: Sanção pecuniária; proibição de licitar pelo prazo de cinco anos aplicada apenas para a empresa líder do cartel e seus administradores. 


\section{Processo Administrativo $\mathrm{n}^{0}$ 08012.001273/2010-24}

Representante: Grupo de Atuação Especial de Recuperação de Ativos e Repressão aos Crimes de Formação de Cartel e Lavagem de Dinheiro do Ministério Público do Estado de São Paulo - GEDEC/MP/SP

Representados: Astéria Incorporações e Construções Ltda.; Aquecedor Solar Transsen Ltda.; Tuma Instalações Térmicas Ltda.; Associação Brasileira de Refrigeração, Ar Condicionado, Ventilação e Aquecimento; Enalter Engenharia, Indústria e Comércio Ltda.; Bosch Termotecnologia Ltda. (nova denominação da Heliotek Máquinas e Equipamentos Ltda.); Sol Tecnologia em Energias Renováveis e Obras Ltda. (antiga Soletrol Tecnologia em Energias Renováveis e Obras Ltda.); José Ronaldo Kulb e Paulo Sérgio Ferrari Mazzon

Relator: Conselheiro Márcio de Oliveira Júnior

Voto-vista: Conselheiro João Paulo de Resende

Julgamento: 16 de setembro de 2015.

Mercado: Fornecimento de aquecedores solares.

Tipologia do Cartel: Rodízio de propostas; apresentação de propostas fictícias; bloqueio em pregão presencial.

Penalidades: Sanção pecuniária.

\section{Processo Administrativo $\mathrm{n}^{0}$ 08012.009885/2009-21}

Representante: Companhia de Saneamento Básico do Estado de São Paulo (SABESP)

Representados: SAENGE Engenharia de Saneamento e Edificações Ltda;; ÔNIX Construções S.A. (atual denominação de CONCIC Construções Especiais S.A.); Luiz Arnaldo 
Pereira Mayer; Marcos Assumpção Pacheco de Medeiros; Antonio Silva de Góes; João Antônio da Silva Saramago; Paulo Bie; Marcus Perdiz da Silva

Relatora: Conselheira Ana Frazão

Julgamento: 8 de abril de 2015.

Mercado: Execução de obras - Sistema Produtor de Água Mambu Branco

Tipologia do Cartel: Subcontratação da empresa perdedora (única licitação).

Penalidades: Sanção pecuniária.

\section{Processo Administrativo $\mathrm{n}^{0}$ 08012.008184/2011-90}

Representante: Câmara Municipal de Jahu/São Paulo

Representados: Consladel Construtora e Laços Detetores e Eletrônica Ltda., Ensin Empresa Nacional de Sinalização e Eletrificação Ltda., Arco-Íris Sinalização Viária Ltda., Faconstru Construção, Sinalização, Administração e Participações Ltda., Ilumi-Tech Construtora Civil e Iluminação Ltda. e Orbstar Indústria, Comércio e Serviços Ltda.

Relator: Conselheiro Gilvandro Vasconcelos Coelho de Araujo

Julgamento: 8 de abril de 2015.

Mercado: Serviços de apoio, sinalização, monitoramento, manutenção e fiscalização do trânsito.

Tipologia do Cartel: : Rodízio de propostas; apresentação de propostas fictícias.

Penalidades: Sanção pecuniária. 


\section{Processo Administrativo $\mathrm{n}^{\circ}$ 08012.008507/2004-16}

Representante: Instituto Nacional do Seguro Social em Bauru (SP) e Procuradoria Federal Especializada do Instituto Nacional do Seguro Social em Osasco (SP).

Representados: Associação Brasileira de Ortopedia Técnica - ABOTEC, Estar Bem Aparelhos Ortopédicos e Podologia Ltda. EPP, Casa Ortopédica Philadélfia Ltda., Ortopedia Belo Horizonte Ltda., Ortolab Órtese e Prótese Ltda., Ortoservice Comércio e Serviços Ortopédicos Ltda., Ortopedia A Especialista Ltda., Ortopedia Americana Ltda., Ortopedia Fubelle Ltda., Ortopedia Germânia Ltda., Ortopedia Kamia Ltda. ME, Ortopedia Lapa Ltda. e Ortopedia Mathias Ltda. EPP.

Relator: Conselheiro Gilvandro Vasconcelos Coelho de Araújo

Julgamento: 10 de dezembro de 2014

Mercado: Fornecimento de órteses e próteses ortopédicas.

Tipologia do Cartel: Rodízio de propostas; apresentação de propostas fictícias; fixação de tabela de preços.

Penalidades: Sanção pecuniária; proibição de licitar pelo prazo de cinco anos aplicada a todos os membros do cartel.

\section{Processo Administrativo $\mathrm{n}^{\circ}$ 08012.009611/2008-51}

Representante: Secretaria de Direito Econômico ex officio

Representadas: Atto Indústria e Comércio de Equipamentos de Segurança Ltda., Beringhs Indústria e Comércio Ltda., leco Desenvolvimento e Indústria de Máquinas e Aparelhos Ltda., Mineoro Indústria Eletrônica Ltda., MPCI Metal Protector Ltda., Preserv Manutenção Eletrônica Ltda., SDM Sistemas de Detectores de Metais Ltda., Carlos Alberto Kapper Damasio, Cléber Francisco Rizzo, José Diogo Fernandes Damasio, Juliano Inácio Paviani, 
Ledair Malheiros Bogado, Luiz Moacir Zermiani, Michel Joseph Stephanne Simon, Nathalie Simon, Patrícia Alves de Jesus e Rochele Rhoden

Relator: Conselheiro Gilvandro Vasconcelos Coelho de Araujo

Julgamento: 10 de dezembro de 2014

Mercado: Fornecimento de portas de segurança detectoras de metais.

Tipologia do Cartel: Rodízio de propostas; apresentação de propostas fictícias; fixação de tabela de preços.

Penalidades: Sanção pecuniária; proibição de licitar pelo prazo de cinco anos aplicada a todos os membros do cartel.

\section{Processo Administrativo $\mathrm{n}^{\circ}$ 08012.006199/2009-07}

Representante: Anônimo

Representadas: Auto Tintas Lages Ltda.; Carlos Luciano Zago; Clima Service Refrigeração Ltda.; Climatintas Ltda.; Ivandel Cordova Burigo Junior; José Carlos Zago; JZago Materiais de Construção Ltda.; Marcelo Pedro Possamai; Tiago Sandi e Zago Ferragens e Materiais de Construção Ltda.

Relator: Conselheiro Márcio de Oliveira Júnior

Julgamento: 10 de dezembro de 2014 .

Mercado: Fornecimento de material de pintura e material hidráulico.

Tipologia do Cartel: Apresentação de propostas fictícias; bloqueio em pregão presencial.

Penalidades: Sanção pecuniária; proibição de licitar pelo prazo de cinco anos aplicada a todos os membros do cartel. 


\section{Processo Administrativo $\mathrm{n}^{0} 08012.011853 / 2008-13$}

Representante: Ministério Público do Estado do Rio Grande do Sul

Representados: Coletare Serviços Ltda., Simpex Serviços de Coleta Transporte e Destino Final de Resíduos Ltda., Wambass Transportes Ltda., Cícero Leopoldo da Silva, Diógenes Duarte Bueno, Ermínio César de Lima Samboranha, Everton Leandro da Silva, Ivan Luis Basso, João Manoel da Silva, Minam Fernanda Brustolin Ávila, Natália Daiane da Silva, Rita de Cássia da Silva, Sérgio Jesus Cruz Angelo.

Relator: Conselheiro Eduardo Pontual Ribeiro

Julgamento: 5 de fevereiro 2014.

Mercado: Serviços de coleta e destinação final de resíduos sólidos.

Tipologia do Cartel: Rodízio de propostas; apresentação de propostas fictícias.

Penalidades: Sanção pecuniária; publicação do extrato da decisão condenatória em jornal de grande circulação.

\section{Processo Administrativo n. 08012.010362/2007-66}

Representante: Ministério Público Federal do Distrito Federal

Representados: Skymaster Airlines Ltda., Brazilian Express Transportes Aéreos Ltda., Luiz Otávio Gonçalves e Antônio Augusto Conceição Morato Leite Filho.

Relator: Conselheiro Ricardo Machado Ruiz.

Mercado: Serviços de transporte aéreo de cargas.

Tipologia do Cartel: Rodízio de propostas; apresentação de propostas fictícias. 
Penalidades: Sanção pecuniária; publicação do extrato da decisão condenatória em jornal de grande circulação.

\section{Processo Administrativo $\mathrm{n}^{\circ}$ 08012.001826/2003-10}

Representante: Secretaria de Direito Econômico

Representados: Airton Rolim Araújo; Alexandre Luzardo da Silva; Angra Log. De Segurança S/C Ltda; Antônio Carlos Coelho; Antônio Carlos Fontag; Ari Dalbem; ASSEVIRGS-Associação das Empresas de Vigilância do Rio Grande do Sul; Caio Alberto Cortina Souza; Caio Flavio Quadros dos Santos; Cláudio Laude; Délcio Rubenich; Delta Serviços de Vigilância Ltda.; EBV-Empresa Brasileira de Vigilância; Edegar Vieira Rolim; EPAVI-Empresa Portoalegrense de Vigilância Ltda; Evandro Vargas; J.M. Guimarães Empresa de Vigilância Ltda.; Joel Valdermir Eich; Jorge Luiz Vieira Rolim; José Renato Quadros; Luiz Fernando Fernandez; Luiz Fernando Vieira; Luiz Osmar Duarte do Amaral; Mario Haas; MD Serviços de Segurança Ltda.; Mobra Serviços de Vigilância Ltda.; Nilton Reginaldo; Osmar Maciel Guedes; Patrícia Ghen; Paulo Elder Bordin; Paulo Renato Pacheco; Protege Serviços de Vigilância Ltda.; Protevale Vigilância e Segurança Ltda.; Reação Segurança e Vigilância Ltda.; Ronaldo Carvalho; Rota-Sul Empresa de Vigilância Ltda.; Rubem Isnar Baz Oreli; Rudder Segurança Ltda.; Secure Sistemas de Segurança Ltda.; Segurança e Transporte de Valores Panambi Ltda.; Seltec Vigilância Especializada Ltda.; Sênior Segurança Ltda.; Sérgio González; Silvio Renato Medeiros Pires; Sindi-Vigilantes do Sul; Tânia E.Euler; Vigilância Antares Ltda.; Vigilância Asgarras S/C Ltda.; Vigilância Patrulhense S/C Ltda.; Vigilância Pedrozo Ltda.; Vigitec; Vivaldi Pereira Rodrigues.

Relatora: Conselheiro Abraham Benzaquem Sicsú

Julgamento: 4 de abril de 2007.

Mercado: Serviços de vigilância.

Tipologia do Cartel: Rodízio de propostas; apresentação de propostas fictícias. 
Penalidades: Sanção pecuniária; proibição de licitar pelo prazo de cinco anos aplicada a todos os membros do cartel.

\section{Processo Administrativo $\mathrm{n}^{0} 08012.006989 / 1997-43$}

Representante: Secretaria de Direito Econômico

Representados: Viação N. S. de Lourdes S/A; Auto Viação Três Amigos S/A; Auto Viação Jabour Ltda.; Viação Madureira Candelária Ltda.; Viação Vila Real Ltda.; Viação Acari S/A e Santa Maria Turismo Ltda.

Relatora: Conselheiro Luis Fernando Rigato Vasconcellos

Julgamento: 15 de junho de 2005.

Mercado: Serviço de transporte público coletivo.

Tipologia do Cartel: Supressão de propostas; subcontratação da empresa perdedora.

Penalidades: Sanção pecuniária; publicação do extrato da decisão condenatória em jornal de grande circulação.

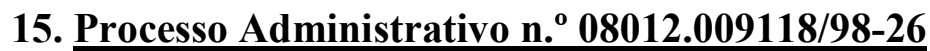

Representante: SDE "ex officio"

Representadas: Estaleiro Eisa S/A e Marítima Petróleo Engenharia Ltda.

Relator: Conselheiro João Bosco Leopoldino da Fonseca

Julgamento: 27 de junho de 2001

Mercado: Execução de obras de reforma de plataforma de petróleo

Tipologia do Cartel: Compensação financeira à empresa perdedora. 
158

Penalidades: Sanção pecuniária. 